November 2007

\title{
Annual Fecundity of Tautog in Long Island Sound: Size Effects and Long-Term Changes in a Harvested Population
}

Lori H. LaPlante

St.Anselm College, llaplante@anselm.edu

Eric T. Schultz

University of Connecticut - Storrs, eric.schultz@uconn.edu

Follow this and additional works at: https://opencommons.uconn.edu/eeb_articles

\section{Recommended Citation}

LaPlante, Lori H. and Schultz, Eric T., "Annual Fecundity of Tautog in Long Island Sound: Size Effects and Long-Term Changes in a Harvested Population" (2007). EEB Articles. 10.

https://opencommons.uconn.edu/eeb_articles/10 


\title{
Annual Fecundity of Tautog in Long Island Sound: Size Effects and Long-Term Changes in a Harvested Population
}

\author{
Lori Hosaka LaPlante ${ }^{1}$ and Eric T. Schultz* \\ Department of Ecology and Evolutionary Biology, University of Connecticut, \\ 75 North Eagleville Road, Storrs, Connecticut, 06269-3043, USA
}

\begin{abstract}
Few studies estimate the impact of individual size on annual reproductive output, which is an important consideration where size-selective harvest may truncate size distributions and sharply reduce populationwide reproductive potential. We conducted a 2-year study of reproduction in field-collected and captive tautog Tautoga onitis from Long Island Sound to investigate the influence of individual size on components that constitute annual fecundity: batch fecundity, spawning frequency, and season duration. Estimates of spawning frequency in field-caught females relied on time-varying features of postovulatory follicles that we validated in experiments conducted on captive spawners. Mature females collected in the wild demonstrated midseason peaks in spawning frequency and batch size. Both spawning frequency and batch fecundity increased significantly with size. As a result, annual fecundity increased sharply with size: large $(500-\mathrm{mm})$ females produced $24-86$ times as many eggs as did small (250-mm) females. Average (400-mm) females spawned 10-16 million eggs over a season, or about 10,000 eggs/g of whole body mass. We estimated temporal changes in populationwide egg production with data from a 22-year trawl survey in Long Island Sound. Over this period, an index of abundance declined by a factor of six and size distributions shifted to smaller fish. Despite the shift in size distribution, estimated annual egg production declined no more than the index of abundance because the sex ratio of the population has become female biased. Estimates of tautog annual fecundity were higher than those reported previously in the southern portion of the species' range, reflecting genetic differentiation or phenotypic responses to environmental effects. Given the relatively large reproductive output of large females, their abundance is likely to influence the rate of population recovery in Long Island Sound.
\end{abstract}

Individual differences warrant close study because they affect population-level processes. It is now well recognized that population dynamics are strongly influenced by differences in behavior and life history among individuals (Lowerre-Barbieri et al. 1998; Hoelker and Breckling 2005; Mazaris and Matsinos 2006). Therefore, it is critical that we develop accurate estimates of how important demographic parameters, such as fecundity, are dependent on features that vary sharply among individuals, such as size. Recent studies have demonstrated the importance of size on survival (Sogard 1997; Munch et al. 2003), reproductive timing (Schultz et al. 1991), and offspring viability (Buckley et al. 1991; Trippel et al. 1997; Scott et al. 1999). Population viability is strongly enhanced when larger, older individuals are retained (Trippel et al. 1997; Berkeley et al. 2004). In the present study, we quantify the influence of female size on annual reproductive output in a population of tautog Tautoga onitis and scale up size-dependent annual fecundity (AF) to estimate

\footnotetext{
* Corresponding author: eric.schultz@uconn.edu

${ }^{1}$ Present address: Department of Biology, Saint Anselm College, 100 Saint Anselm Drive, Manchester, New Hampshire, 03102, USA.
}

Received November 19, 2006; accepted June 5, 2007 Published online November 15, 2007 how population-level output of eggs has changed over a period of harvest and declining abundance.

Annual fecundity, a parameter of individual reproductive output, is strongly size dependent. Many marine fishes are multiple (heterochronal) spawners; in such cases, evaluating $\mathrm{AF}$ for an individual requires combining information on batch fecundity (BF), spawning frequency (SF), and season duration (Hunter et al. 1985). The positive effect of size on BF is well documented (Marteinsdottir and Begg 2002), typically conforming closely to an isometric relationship in which the number of eggs is proportional to the third power of length (Bagenal 1978). Larger, older females can also have relatively longer spawning seasons (DeMartini and Fountain 1981; Parrish et al. 1986) and spawn more frequently (Schultz and Warner 1991; Ganias et al. 2003) than smaller females. Thus, the combined and interactive effects of size on spawning duration, frequency, and clutch size must be taken into account in quantifying the size dependence of AF.

Accurate estimates of AF in multiple spawners must take careful account of seasonal environmental effects. Reproductive output often peaks in the middle of the breeding season when temperature and food resources are high (Alheit 1988; DeMartini 1991; Lisovenko and Andrianov 1991). Environmental variability may have 
disparate effects on individuals of different sizes (Parrish et al. 1986; DeMartini 1991), so it is especially useful to conduct studies that can track seasonal effects for multiple size-classes.

Tautog are common demersal fish occurring in temperate waters from Nova Scotia to South Carolina (Munroe 2002). The species is gonochoristic, and males and females become sexually mature at 218 and $224 \mathrm{~mm}$, respectively (White et al. 2003). Tautog spawn multiple times during the breeding season (April-September) at inshore and nearshore sites (Arendt et al. 2001; Munroe 2002). Laboratory studies by Olla and Samet (1977) showed that male and female tautog begin courtship in the morning and spawn between 1300 and 1600 hours. Spawning occurs when a pair rushes towards the surface of the water and releases gametes in synchrony (authors' personal observations). Tagging studies have shown that tautog return to the same locales to spawn year after year (Cooper 1966), which likely increases their vulnerability to local fishing pressures. The tautog is a popular food and sport fish; recreational harvest exceeds commercial harvest in all states (Atlantic States Marine Fisheries Commission 2006). Biomass and spawning stock biomass have been declining throughout the species' range for roughly two decades, prompting efforts to manage the species. Nonetheless, a recent stock assessment indicated that fishing mortality frequently exceeds target values (Atlantic States Marine Fisheries Commission 2006). This species' vulnerability to overfishing is exacerbated by slow growth rates (von Bertalanffy specific growth rate $K=$ 0.09-0.15: Cooper 1967; Hostetter and Munroe 1993), long life span (maximum age $=34$ years: Cooper 1967), orientation to structure, and site fidelity (e.g., Cooper 1966, 1967; Hostetter and Munroe 1993; Arendt et al. 2001). States presently restrict recreational catch via combinations of restricted seasons, minimum size, and creel limits. The structure of the population has probably shifted towards smaller and younger fish, as commonly occurs in fisheries (Williams and Shertzer 2005). Indeed, changes in recreational harvest size distributions appear to reflect losses of larger fish (Atlantic States Marine Fisheries Commission 2006). With losses of the largest size-classes of females, population reproductive output is likely to decline more sharply than its abundance, potentially leading to recruitment overfishing (Berkeley et al. 2004).

The present study was undertaken to improve our estimates of individual- and population-level reproductive output in tautog. White et al. (2003) correctly noted that previous fecundity estimates in tautog (e.g., Stolgitis 1970) were for BF only; they estimated AF in Virginia tautog but did not assess size differences in SF or season duration. Our field sampling of tautog in Long Island Sound (LIS) was designed to capture these size effects. We conducted experiments on captivespawning tautog to test for temperature dependence in histological changes (i.e., postovulatory follicle [POF] development) that indicate the time since last spawning and thus SF; this ensured that seasonal changes in both $\mathrm{BF}$ and SF were accounted for properly. Individuallevel data on reproductive output were scaled up to the population level with a 22-year trawl survey data set of abundance and size structure in LIS to test whether there has been a disproportional decline in egg production because of size structure truncation. The extent to which there is geographical separation of tautog into separate stocks remains unclear (see Discussion), and we refer to LIS tautog as a population without implying such separation from tautog in other parts of their range.

\section{Methods}

Postovulatory follicle analysis.-Evaluating SF requires estimating the proportion of mature females spawning each day of collection based on the frequency of females with ovaries containing hydrated oocytes (DeMartini and Fountain 1981) or POFs of known age (Hunter and Macewicz 1985). Spawning is typically imminent for a female with hydrated oocytes. After hydration, oocytes move into the lumen of the ovaries (i.e., ovulation), leaving behind POFs in the ovarian tissue. Aging of POFs is done through microscopic examination of histologically prepared ovaries. The age of POFs provides information on how recently an individual has spawned. Controlled laboratory experiments are necessary for developing criteria (e.g., cell types and structure of thecal layer) used to age POFs and must be species specific (Hunter and Macewicz 1985).

The tautog used for developing POF criteria were collected with otter trawls and traps throughout LIS in 2000 (May-August) and 2001 (May). All fish were acclimated for at least $2 \mathrm{~d}$ in a large-group outdoor holding tank $(1,665 \mathrm{~L})$. We then size-matched malefemale pairs and placed each pair in a smaller outdoor tank (340 L for smaller fish; $795 \mathrm{~L}$ for larger fish). All tanks were fitted with $70 \%$ shade cloth to simulate natural light conditions and received continuous aeration and filtered seawater from LIS. Fish were fed a daily ad libitum diet of green crabs Carcinus maenas, mussels Mytilus edulis, and hermit crabs Pagurus spp. Each tank contained a data logger that recorded water temperature every $10 \mathrm{~min}$, and an egg trap constructed of $0.33-\mathrm{mm}$ mesh was set at the outflow and monitored daily. Females were sacrificed during or after spawning as described below, and males 
were retained for additional trials; 27 females paired with 12 males were used to develop POF criteria.

The experiments were designed to develop criteria for distinguishing between POFs that formed on the day of collection, termed day 0 (i.e., within $12 \mathrm{~h}$, because tautog are diurnal), from those that formed on the previous day, termed day 1. Initial experiments revealed that no POFs were visible after $48 \mathrm{~h}$. We ran experiments in different months (one monthly in JuneAugust 2000 and June-July 2001) to reveal whether water temperature (range $=14.1-20.3^{\circ} \mathrm{C}$ ) or other seasonal effects influenced the degeneration of POFs. Experiments were initiated when tanks were populated with pairs. Each day, egg traps were set at 0900 hours and checked hourly. A trial of the experiment began at the hour when eggs were first observed in a trap; at that time, the female was randomly assigned a sacrifice time $(3,6,12,18,21,24,30,42$, and $45 \mathrm{~h}$ postspawning). We removed the male on the first evening of the trial in order to discourage the female from spawning a new batch of eggs on a subsequent day, and we continued monitoring egg traps to confirm that no additional eggs were released. At the designated time, females were euthanized. Ovaries were immediately fixed in $10 \%$ neutrally buffered formalin for $2 \mathrm{~d}$ and were stored in $70 \%$ ethanol.

One ovary from each female was randomly selected and processed. Tissue samples of the ovary were dehydrated (Leica Model TP1050) and embedded with Paraplast (Fisher Tissue Path) at $60^{\circ} \mathrm{C}$ on a work platform (Surgipath; Model 300X). Embedded blocks were cooled to $-7^{\circ} \mathrm{C}$, sectioned at $4 \mu \mathrm{m}$, and stained with hematoxylin and eosin; the sections were then mounted (Permount) on slides. We examined prepared slides at $400 \times$ magnification (Zeiss Axioscop).

Collection and processing of specimens for annual fecundity analysis.-Female tautog were collected in 2000 and 2001 from rocky reefs in eastern LIS within 4 $\mathrm{km}$ of Millstone Point, Waterford, Connecticut $\left(41^{\circ} 18^{\prime} \mathrm{N}, 72^{\circ} 10^{\prime} \mathrm{W}\right)$. We collected specimens using scuba and spearguns, which permitted us to select females within desired size-classes. Collection typically began in midmorning and concluded at 1300 hours, the time at which spawning was expected to commence. Sampling trips were timed to the midpoint of 2week periods (Table 1); $1 \mathrm{~d}$ of sampling was needed in most periods, but we collected for a second day in some periods if catch rates were poor during the first outing. We stopped sampling for the season when all ovaries were scored in the resting stage, indicating that females had ceased reproductive activity for the season. Females were immediately processed upon capture. Time of sacrifice, total wet mass $( \pm 1.0 \mathrm{~g})$, ovary mass $( \pm 1.0 \mathrm{~g})$, standard length $( \pm 1.0 \mathrm{~mm})$, total length (TL; $\pm 1.0 \mathrm{~mm}$ ), and ovary stage (based on White et al. 2003) were recorded. Ovaries were fixed in $10 \%$ neutrally buffered formalin for $2 \mathrm{~d}$ and then were stored in $70 \%$ ethanol. A small percentage $(<5 \%)$ had ovaries that were damaged by collection and were discarded.

Estimation and analysis of batch fecundity.-One ovary from each female was randomly selected for estimating $\mathrm{BF}$, and the other was used for SF (see below). Following the methods of Hunter et al. (1985), $\mathrm{BF}$ was estimated from counts of hydrated oocytes in females that had not yet ovulated (i.e. ovaries that lacked day- 0 POFs as determined by histological analysis; $n=48$ in 2000, $n=71$ in 2001). Oocytes were hydraulically removed from ovarian tissue using methods described by Lowerre-Barbieri and Barbieri (1993). Ovarian development and density of oocytes are uniform throughout the tautog ovary and lack positional effects (White et al. 2003). Batch fecundity was estimated from three 5-mL subsamples taken from a slurry of separated oocytes by means of the equation

$$
\mathrm{BF}=2 \times\left[\sum_{i=1}^{3}\left(n_{i} / m_{i}\right) \times m_{t}\right] / 3,
$$

where $n_{i}=$ the number of oocytes in subsample $i, m_{i}=$ the mass of subsample $i( \pm 0.001 \mathrm{~g})$, and $m_{t}=$ the mass of slurry.

The effects of both time of season (i.e., date) and female length on BF were evaluated in an analysis of covariance (ANCOVA). Dates were categorized into 2week periods for this analysis (Table 1). The full model was

$$
{\overline{\log (\mathrm{BF})_{l p}}}_{l}=\beta_{0}+\beta_{1} L+\gamma_{p} P+\gamma_{l p}(L \times P),
$$

where $\overline{\log (\mathrm{BF})}_{l p}$ is the predicted size- and periodspecific $\log _{10}$ transformed fecundity, $L$ is $\log _{10}$ transformed TL, $P$ is a categorical variable representing period, and $L \times P$ is the TL-period interaction. Periods in which no spawning females were collected (periods 7 and 8 in 2000; period 10 in 2001) were not included in the analysis. Preliminary analysis employing a bivariate $\mathrm{BF}-\mathrm{TL}$ regression model without period effects indicated significant between-year differences in elevation and slope. The predicted TL- and periodspecific batch fecundity $\overline{\mathrm{BF}}_{l p}$ was estimated by backtransformation as

$$
\overline{\mathrm{BF}}_{l p}=10^{\overline{\log (\mathrm{BF})}_{l p}} \times 10^{2.302 \mathrm{MSE} / 2},
$$

where MSE is the mean square error in the ANCOVA model. The second term in the product corrects for the slight bias arising from back-transformation of error (Sprugel 1983; Newman 1993). 
TABLE 1.-Design and sample information for reproductive performance analysis of Long Island Sound tautog. Each period is listed by its initial date. The numbers of sampling dates, fish collected, and fish that yielded estimates of batch fecundity are given, along with the mean and range for TL and the mean spawning frequency (SF).

\begin{tabular}{|c|c|c|c|c|c|c|c|}
\hline \multirow[b]{2}{*}{ Period } & \multirow[b]{2}{*}{ Start date } & \multicolumn{3}{|c|}{$N$} & \multicolumn{2}{|c|}{$\mathrm{TL}$} & \multirow[b]{2}{*}{ Mean SF } \\
\hline & & Dates & Fish & $\mathrm{BF}$ & Mean & Range & \\
\hline \multicolumn{8}{|c|}{2000} \\
\hline 1 & Jun 8 & 2 & 12 & 7 & 358 & $176-436$ & 0.86 \\
\hline 2 & Jun 22 & 0 & & & & & \\
\hline 3 & Jul 6 & 2 & 29 & 25 & 367 & $265-535$ & 0.90 \\
\hline 4 & Jul 20 & 0 & & & & & \\
\hline 5 & Aug 3 & 1 & 16 & 12 & 396 & $315-548$ & 0.88 \\
\hline 6 & Aug 17 & 1 & 13 & 4 & 379 & $240-480$ & 0.58 \\
\hline 7 & Aug 31 & 1 & 20 & 0 & 365 & $262-431$ & 0 \\
\hline 8 & Sep 14 & 1 & 21 & 0 & 403 & $220-530$ & 0 \\
\hline \multicolumn{8}{|c|}{2001} \\
\hline 0 & May 7 & 1 & 0 & & & & \\
\hline 1 & May 21 & 2 & 7 & 2 & 412 & $322-490$ & 0.86 \\
\hline 2 & Jun 4 & 2 & 15 & 14 & 391 & $237-507$ & 0.83 \\
\hline 3 & Jun 18 & 1 & 14 & 13 & 371 & $245-575$ & 0.89 \\
\hline 4 & Jul 2 & 1 & 13 & 12 & 343 & $272-415$ & 0.92 \\
\hline 5 & Jul 16 & 1 & 16 & 12 & 278 & $225-364$ & 0.67 \\
\hline 6 & Jul 30 & 1 & 19 & 18 & 374 & $250-515$ & 0.87 \\
\hline 7 & Aug 13 & 1 & 14 & 4 & 353 & $196-455$ & 0.50 \\
\hline 8 & Aug 27 & 1 & 15 & 4 & 385 & $250-570$ & 0.40 \\
\hline 9 & Sep 10 & 1 & 10 & 1 & 398 & $208-543$ & 0.15 \\
\hline 10 & Sep 24 & 1 & 14 & 0 & 345 & $265-500$ & 0 \\
\hline
\end{tabular}

Estimation and analysis of spawning frequency.Ovary samples were prepared for histology and examined as described above for the presence of the following features: hydrated oocytes, day-0 POFs, and day-1 POFs. We estimated SF over a 2-d interval (Table 2). Females containing ovaries that had none of these features were scored as having spawned zero times in the last $2 \mathrm{~d}(\mathrm{SF}=0)$. Females with evidence of same-day spawning (hydrated oocytes, day-0 POFs, or both; indicating that spawning was imminent or had just occurred) or day-1 POFs were scored as having spawned once in the last $2 \mathrm{~d}(\mathrm{SF}=0.5)$. Those with evidence of same-day spawning and day-1 POFs were

TABLE 2.- Method used to estimate tautog spawning frequency using an individual-based postovulatory follicle (POF) method. The spawning frequency (SF) for each female was scored based on the presence $(+)$ or absence $(-)$ of hydrated oocytes and POFs formed on the day of collection (day-0 POFs) or the day preceding collection (day-1 POFs).

\begin{tabular}{cccc}
\hline $\mathrm{SF}^{\mathrm{a}}$ & Hydrated oocytes & Day-0 POFs & Day-1 POFs \\
\hline 0 & - & - & - \\
0.5 & + & + & - \\
0.5 & + & - & - \\
0.5 & - & + & - \\
0.5 & - & + & + \\
1 & + & - & + \\
1 & + & + & + \\
1 & - & + \\
\hline
\end{tabular}

${ }^{\mathrm{a}} 0=$ no spawning event; $0.5=1$ event; $1=2$ events. scored as having spawned twice in the last $2 \mathrm{~d}(\mathrm{SF}=1)$. The mean SF for each period was estimated as the sum of individual SF values divided by the number of possible spawns (number of individuals $\times 2$ ).

We analyzed the combined effects of date and female length on SF via logistic regression. As in the $\mathrm{BF}$ analysis, dates were categorized into 2-week periods for this analysis (Table 1), and periods in which no spawning females were collected were not included in the analysis. The full model was

$$
\begin{aligned}
\operatorname{logit}\left(\overline{\mathrm{SF}}_{l p}\right) & \equiv \log _{e}\left[\overline{\mathrm{SF}}_{l p}\left(1-\overline{\mathrm{SF}}_{l p}\right)^{-1}\right] \\
& =\beta_{0}+\beta_{1} L+\beta_{2} P,
\end{aligned}
$$

where $\overline{\mathrm{SF}}_{l p}$ represents the predicted size-class- and period-specific value of SF, $L$ is length (a continuous variable), and $P$ is period (a classification variable). Because the effect of period was significant each year (see Results), we conducted separate bivariate logistic regression analyses of the size effect for each year and period, that is,

$$
\operatorname{logit}\left(\overline{\mathrm{SF}}_{l p}\right) \equiv \log _{e}\left[\overline{\mathrm{SF}}_{l p}\left(1-\overline{\mathrm{SF}}_{l p}\right)^{-1}\right]=\beta_{0}+\beta_{1} L
$$

The logit was back-transformed to yield $\overline{\mathrm{SF}}_{l p}$, the predicted length- and period-specific SF.

Mass-length relationships.-We analyzed female wet mass-length relationships via linear regression and 
ANCOVA. Prediction of wet mass was needed for expressing AF in mass-relative terms (see below). Both wet mass and length were $\log _{10}$ transformed for these analyses. We tested for interannual differences in mass-length scaling relationships by including year as a classification variable in the ANCOVA. The full ANCOVA model was

$$
\log \left(\overline{\mathrm{WM}}_{L y}\right)=\beta_{0}+\beta_{1} L+\gamma_{y} Y+\gamma_{l y}(L \times Y),
$$

where $\overline{\log (\mathrm{WM})}_{L y}$ is the predicted wet mass, $L$ is $\log _{10}$ transformed TL, $Y$ is a categorical variable representing period, and $L \times Y$ is the TL-year interaction. After examination of results from the full model, nonsignificant interaction terms were dropped. To estimate wet mass at length for different size-classes in each year, we conducted separate bivariate regressions of logtransformed mass versus TL and back-transformed as

$$
\overline{\mathrm{WM}}_{L y}=10^{\overline{\log (\mathrm{WM})}_{L y}} \times 10^{2.302 \mathrm{MSE} / 2},
$$

where MSE is the mean square error in the regression.

Because we found interannual differences in AF, we also tested for differences in female condition. The condition variable we tested was nonreproductive wet mass (i.e. total wet mass minus ovary mass, adjusted for length). These analyses were conducted via ANCOVA and separate bivariate regressions for each year.

Estimation of annual fecundity.-The results from the above analyses were combined and interpolated for estimates of size-specific AF. Mean size-specific AF $\left(\overline{\mathrm{AF}}_{l}\right)$ was estimated in two models, with and without size dependence in SF (full and reduced models, respectively). The full model that included size dependence in SF was

$$
\mathrm{AF}_{l}=\sum_{d=\alpha}^{\infty} \overline{\mathrm{BF}}_{l d} \times \overline{\mathrm{SF}}_{l d}
$$

where $d$ is date and $\overline{\mathrm{BF}}_{l d}$ and $\overline{\mathrm{SF}}_{l d}$ are the predicted length- and date-specific BF and SF, $\alpha$ is the first date of the spawning season, and $\varpi$ is the last date of the spawning season. The reduced model that did not include size dependence in SF was

$$
\mathrm{AF}_{l}=\sum_{d=\alpha}^{\varpi} \overline{\mathrm{BF}}_{l d} \times \overline{\mathrm{SF}},
$$

where $\overline{\mathrm{SF}}$ is the year's mean SF over all lengths and dates. Values for $\overline{\mathrm{BF}}_{l d}$ and $\overline{\mathrm{SF}}_{l d}$ were derived from the period-specific $\overline{\mathrm{BF}}_{l p}$ and $\overline{\mathrm{SF}}_{l p}$. For dates corresponding to the first date of a sampling period (e.g., 6/8 for period 1 in 2000), $\overline{\mathrm{BF}}_{l d}$ and $\overline{\mathrm{SF}}_{l d}$ were set to the periodspecific values estimated from the regression models described above (equations 2, 3, and 5). The first date of the season ( $\alpha$ ) was set to June 8 in 2000 and to May 7 in 2001. Spawning was already under way on date $\alpha$ in 2000. For SF and $\mathrm{BF}$ at the beginning of the 2001 season, we assumed $\overline{\mathrm{SF}}_{l \alpha}=0, \overline{\mathrm{BF}}_{l \alpha}=\overline{\mathrm{BF}}_{l \text { May22 }}$. The last date $(\omega)$ was set to August 31 in 2000 and to September 24 in 2001. We assumed $\overline{\mathrm{SF}}_{l \varpi}=0, \overline{\mathrm{BF}}_{l \varpi}=$ $\overline{\mathrm{BF}}_{l \mathrm{Aug} 17}$ in 2000 and $\overline{\mathrm{SF}}_{l \sigma}=0, \overline{\mathrm{BF}}_{l \omega}=\overline{\mathrm{BF}}_{l \text { Sept } 10}$ in 2001. For dates between the first dates of sampling periods, $\overline{\mathrm{BF}}_{l d}$ and $\overline{\mathrm{SF}}_{l d}$ were set by linear interpolation. We report $\overline{\mathrm{AF}}_{l}$ as number of eggs and also as relative fecundity by dividing the number of eggs by the predicted total wet mass of females in each size-class.

Estimation of population-level annual fecundity.Since 1984, the Connecticut Department of Environmental Protection (CDEP) has conducted annual spring and fall trawling surveys in LIS (CDEP 2005). Briefly, the sampling design is as follows. Long Island Sound is mapped for sampling into $1.85 \times 3.7 \mathrm{~km}(1 \times 2$ nautical mi) cells assigned to 12 depth and bottom type strata. Each season, the area is sampled with a 14-m otter trawl (51-mm cod end) using a stratified random design for most of the region that comprises 200 samples/season. Fish and invertebrate species are counted, and selected finfish species (including tautog) are measured to the nearest centimeter, sexed, and aged via analysis of hard parts (e.g., the opercle in tautog). The spring trawl survey data are used to estimate the abundance of tautog, which is summarized as the geometric mean catch in each season. We estimated the abundance of each female size-class based on this abundance index, data on each year's sex ratio, and sex-specific size structure (D. Simpson, CDEP Marine Division, personal communication), and estimated the reproductive potential of the population each year by converting size-class abundance to number of eggs using $\overline{\mathrm{AF}}_{l}$ (equation 6) and 2001 data.

\section{Results \\ Changes in Postovulatory Follicles}

On the evening of the spawning date for a captive pair, we removed the male in an effort to assure that only one egg release would occur and a single timed set of POFs could be evaluated. Indeed, monitoring of egg traps indicated that females did not spawn a subsequent batch of eggs. Oocyte development nonetheless continued in these solitary females, and hydrated oocytes were found as soon as $12 \mathrm{~h}$ after the spawning event.

We were able to distinguish day-0 from day-1 POFs, and the criteria we established for aging were not temperature dependent. Changes in POF characteristics from day 0 to 1 were as expected based on descriptions from White et al. (2003). Day-0 POFs were relatively large in size, exhibiting visible lumina, thick convo- 


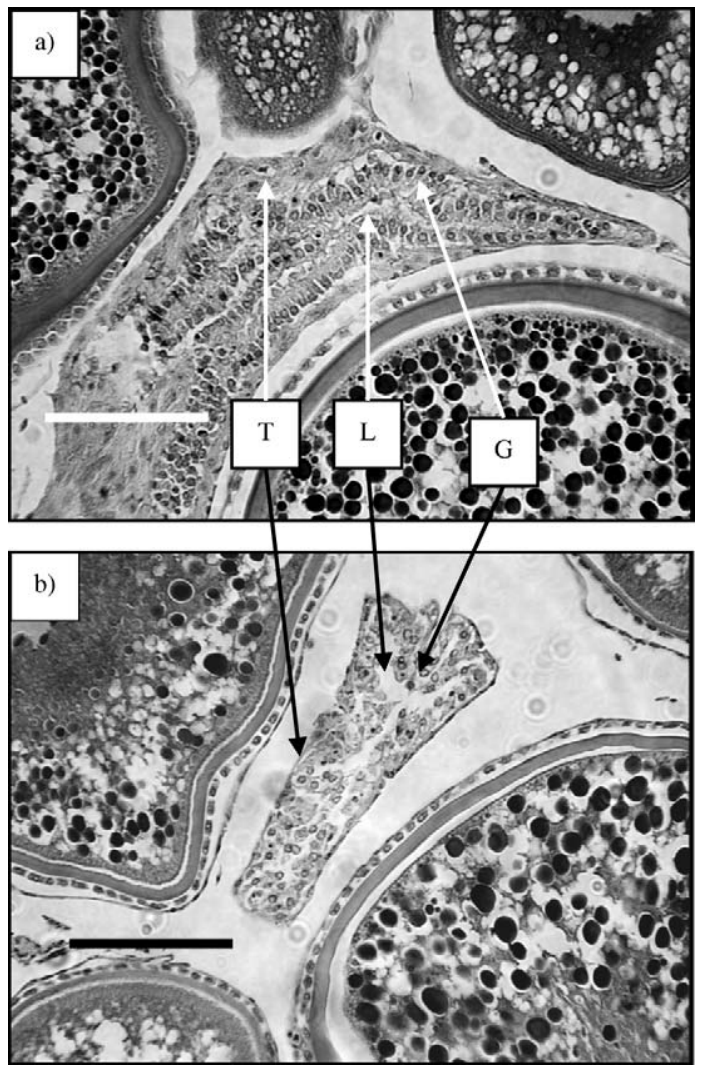

FIGURE 1.-Female tautog postovulatory follicles formed on (a) the day of collection (day 0) and (b) the day preceding collection (day 1). Abbreviations are as follows: $\mathrm{G}=$ granulosa layer, $\mathrm{L}=$ lumen, and $\mathrm{T}=$ thecal layer; bars $=0.1$ $\mathrm{mm}$.

luted thecal layers, convoluted granulosa layers that had columnar cells, and basally located nuclei that were prominent and uniform in shape (Figure 1a). Day-1 POFs were relatively small (size $<50 \%$ of day- 0 POF size) and had a thin thecal layer, a granulosa layer that had little to no structure, and degenerated nuclei of variable shapes (Figure 1b). The effect of temperature on POF criteria was not detectable at the day category level based on microscopic examination of characteristics outlined above.

\section{Effects of Date and Size on Batch Fecundity and Spawning Frequency}

The reproductive season of tautog in LIS was 3-4 months in duration. Spawning was already underway when we commenced sampling in early June 2000. Fish were not present at the site in early May 2001 but arrived and started spawning in the next period (Table 1). Mean SF usually exceeded 0.8 through June and

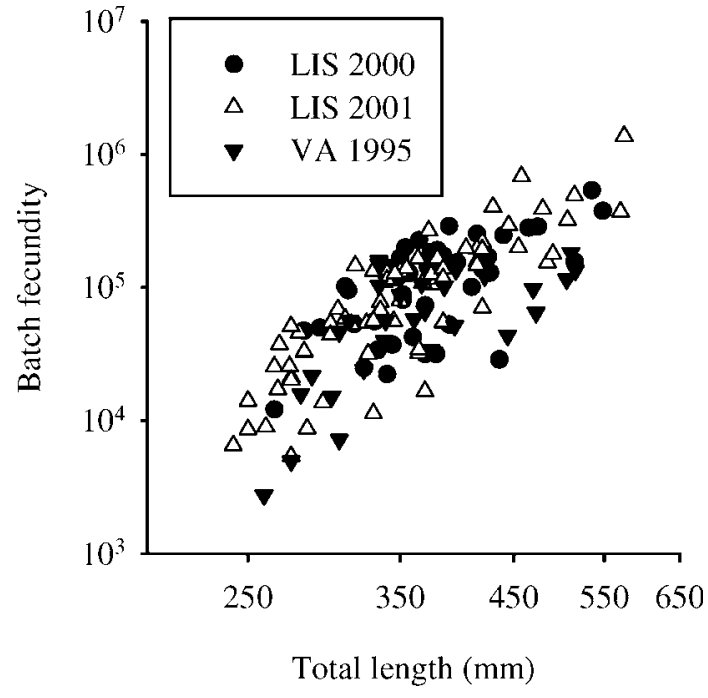

FIGURE 2.--Observed batch fecundity (number of eggs) versus size of female tautog collected during 2000 and 2001 in Long Island Sound (LIS; this study) and during 1995 in Virginia (VA; White et al. 2003).

July. Spawning ceased in late August (2000) or September (2001), although we continued to observe fish at sites.

The effect of female size on BF was strong in both 2000 and 2001 (Figure 2). In preliminary analysis, we eliminated two small 2001 females ( 245 and $270 \mathrm{~mm}$ TL) with low BF (769 and 864 eggs) as outliers (studentized residual of $\log [\mathrm{BF}]>3$; Cook's $D>4 / n$ ). In the full ANCOVA model for BF (equation 2), the length-period interaction was not significant in either year (2000: $F_{1,3}=0.77, P=0.52 ; 2001: F_{1,6}=1.6, P=$ $0.17)$. We therefore repeated the analyses without the interaction. In both years, BF increased significantly with female size (Table 3). In 2000, the observed slope for the size effect was not different from the expected isometric value of 3 ( $t$-test: $t_{43}=1.5$, two-tailed $P=$ $0.15)$. In contrast, the observed slope in 2001 was significantly different from 3 ( $t$-test, $t_{59}=5.6$, twotailed $P<0.00001$ ).

There were significant size-independent differences in BF from period to period (Table 3). In both years, peak values of BF occurred midseason, in July (Figure 3).

Spawning frequency also varied with female size and over the season in each year. While some females had not spawned in the $2 \mathrm{~d}$ before sampling, a few had spawned once and most had spawned twice (Table 1; Figure 4). Larger females were more likely to have spawned in both days preceding sampling. The logistic regression model (equation 4) provided a good fit to 
TABLE 3.-Effect of size and date on the batch fecundity (BF) of female tautog collected in Long Island Sound during 2000 and 2001. Log-transformed female TL (a continuous covariate) and period (a categorical variable) were used as predictors and $\log$-transformed $\mathrm{BF}$ as the response variable. The TL-period interaction was nonsignificant and therefore was excluded from the model.

\begin{tabular}{llrccccrr}
\hline Year & Effect & df & Slope & SE of slope & Mean square & $F$ & $P$ & $R^{2}$ \\
\hline 2000 & TL & 1 & 3.8 & 0.56 & 2.9 & 46 & $<0.0001$ & 0.55 \\
& Period & 3 & & & 0.30 & 4.7 & 0.0064 & \\
& Error & 43 & & & 0.06 & & & \\
2001 & TL & 1 & 5.2 & 0.39 & 0.20 & 3.4 & 0.0028 & \\
& Period & 8 & & & 0.06 & & & \\
& Error & 59 & & & & &
\end{tabular}

the data in both years (i.e., predicted SF was highly concordant with observed SF; Table 4). Spawning frequency varied with size and period in both years. Bivariate logistic regression applied separately to the data from each period revealed that SF consistently increased with size, although the size effect was not significant in most of the single-period data (Figure 5). Among larger females, SF was close to 1 (i.e., they spawned daily) for June and July and declined later in the season.

\section{Mass-Length Relationships}

There was a significant interannual difference in female mass at length. The ANCOVA revealed a significant difference between years in total wet mass at length. Analysis of the full model (equation 6) indicated that the wet mass-length slopes were the same in both years (i.e., no length-year interaction; $F_{1,107}=2.0, P=0.16$ ). In a reduced model without the interaction term, the effect of year was significant $\left(F_{1,108}=15, P=0.0002\right)$. Regressions used for relative fecundity estimates (see below) were $\log$ (total wet mass $)=2.92 \cdot \log (\mathrm{TL})-4.46$ in 2000 and $\log$ (total wet mass $)=3.10 \cdot \log (\mathrm{TL})-4.89$ in 2001 .

Female condition was about $9 \%$ greater in 2001 than in 2000. As with total wet mass, nonreproductive wet mass differed significantly between years $\left(F_{1,108}=8.9\right.$, $P=0.004)$. Using the ANCOVA model, we estimated the log-transformed wet mass at the log-transformed mean female size $(360 \mathrm{~mm})$ and we back-transformed wet mass using equation (7). Predicted wet mass for an average female was $1,012 \mathrm{~g}$ in 2000 and $1,105 \mathrm{~g}$ in 2001.

\section{Effect of Size on Annual Fecundity}

The AF increased with female size in both years and varied between years (Figure 6). An average (400-mm, $1.5-\mathrm{kg}$ ) female spawned about 10 million eggs in 2000 $(7,100$ eggs/g) and about 16 million eggs in 2001 $(11,000 \mathrm{eggs} / \mathrm{g})$. The increase in AF with size was sharper in 2001 than in 2000. In 2000, the AF of the $500-\mathrm{mm}(2.9-\mathrm{kg})$ class of mature females was 24 times greater than that of the $250-\mathrm{mm}(0.36-\mathrm{kg})$ class $(500$ mm: 26 million eggs, or 9,000 eggs/g; $250 \mathrm{~mm}$ : 1 million eggs, or 3,000 eggs/g). In contrast, in 2001 the fecundity of large females was 86 times greater than that of small females $(500 \mathrm{~mm}$ : 55 million eggs, or 19,000 eggs/g; $250 \mathrm{~mm}$ : 0.6 million, or 1,800 eggs/g). The size effect on SF made an appreciable contribution to the AF difference between large and small females. When $\mathrm{AF}$ was estimated using a mean value for SF rather than size-specific values (equation 9 rather than equation 8), the difference between large and small female reproductive performance was reduced (largefemale $\mathrm{AF}$ was 14 times greater in 2000 and 36 times greater in 2001).

\section{Population-Level Annual Fecundity}

The tautog population in LIS has changed considerably since initiation of the trawl survey in 1984 . Tautog abundance has declined by a factor of 6 (Figure $7 \mathrm{~b}$; Pearson's product-moment correlation of index and year: $r=-0.62, P=0.0022$ ). The size structure has shifted to smaller fish: the typical median-size female has declined about $20 \mathrm{~mm}$ (Figure 7a), and there has been a significant decrease in size (Pearson productmoment correlation of female size and year: $r=-0.14$, $P<0.0001)$. The sex ratio has changed from a roughly equitable balance of males and females to one with more females (Figure 7b; proportion female and year: $r$ $=0.74, P<0.0001)$. The decline in estimated annual egg production per area is commensurate with the decline in tautog abundance (Figure 7b; Pearson product-moment correlation of eggs per haul and year: $r=-0.65, P<0.0011)$.

\section{Discussion}

Annual fecundity in LIS tautog varied among individuals as a result of size dependence in both SF and BF. The most fecund individuals were large females, which spawned large batches of eggs virtually every day throughout the season. Small females exhibited higher variability in SF and a slightly shorter season duration. We combined our estimate of sizedependent AF with time series data on abundance and 
a)

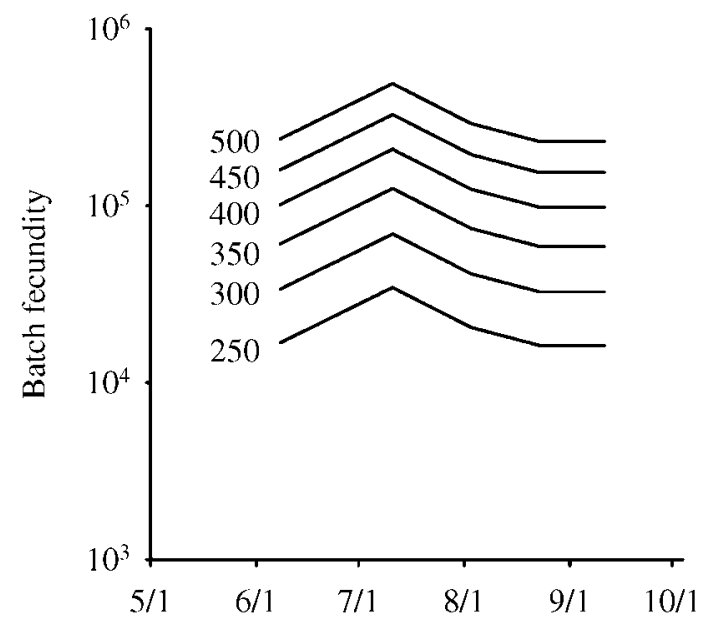

b)

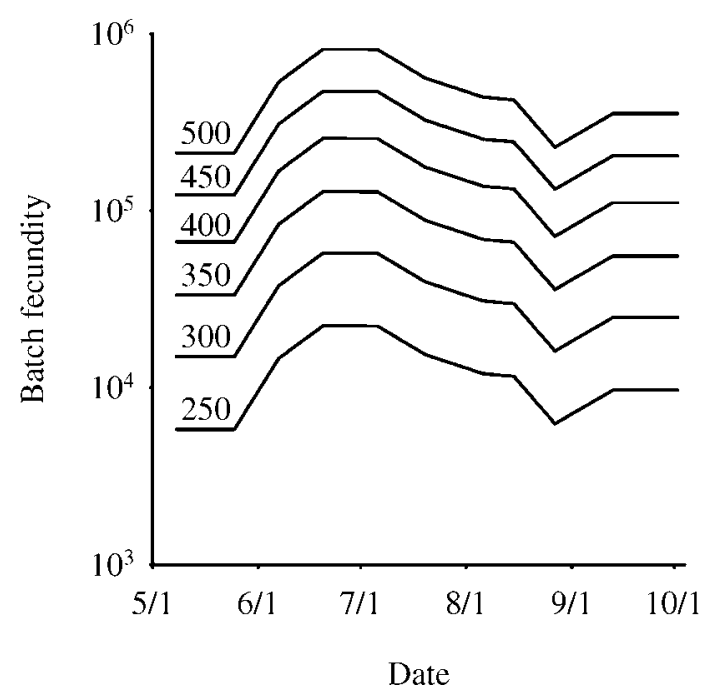

FIGURE 3.-Predicted size- and date-specific batch fecundity of female tautog in Long Island Sound during (a) 2000 and (b) 2001. Batch fecundity is plotted against date based on equation (3). Separate predictions are shown for size-classes ranging from 250 to $500 \mathrm{~mm} \mathrm{TL}$ in $50-\mathrm{mm}$ increments.

size distribution to assess population-level changes in reproductive output. The estimated population-level reproductive output has declined six-fold in 20 years, comparable to the decline in overall abundance. In discussing our results, we first examine several assumptions underlying our analyses; we then consider variability in $\mathrm{AF}$ among years and between populations a)

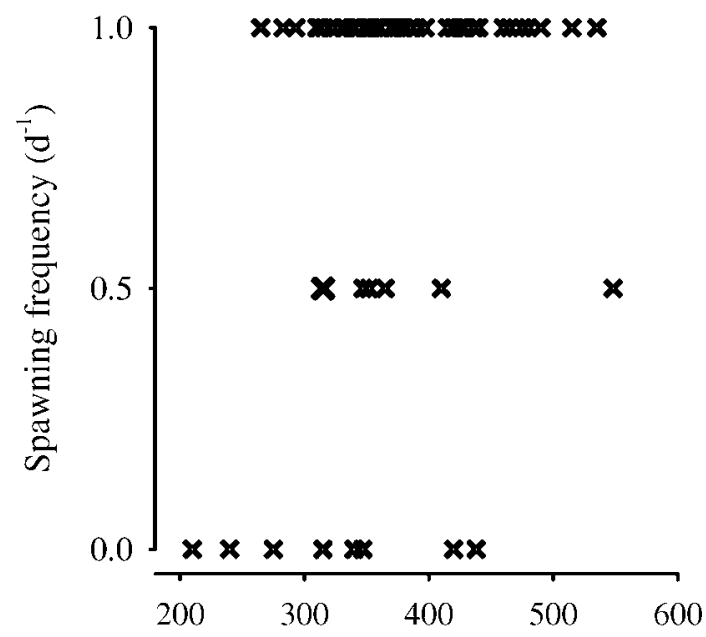

b)

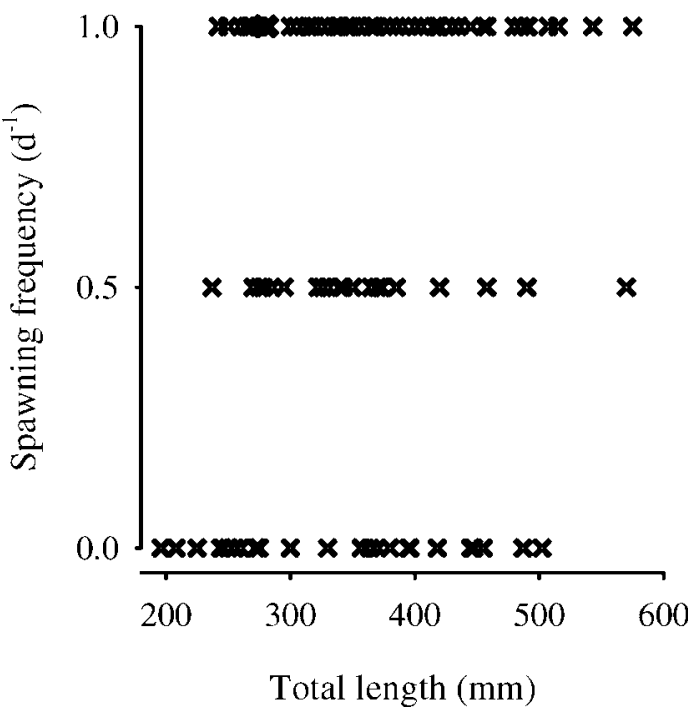

FIGURE 4.- Observed spawning frequency versus size of female tautog in Long Island Sound during (a) 2000 and (b) 2001. Ovaries examined for hydrated oocytes, day-0 postovulatory follicles (POFs), and day-1 POFs were used to determine spawning frequency over the $2 \mathrm{~d}$ prior to sampling $(0=$ no spawning event; $0.5=1$ event; $1.0=2$ events $)$.

(LIS versus Virginia, as reported in White et al. 2003). We also discuss size-dependent $\mathrm{AF}$ and populationlevel changes in reproductive output.

To estimate SF for field-caught females, we used estimates of POF age that were validated using data collected in our captive experiments. Since temperature 
TABLE 4.-Effect of size and date on the spawning frequency (SF) of female tautog collected in Long Island Sound during 2000 and 2001. Female TL (a continuous variable) and period (a categorical variable) were predictors and SF was the response variable in logistic regression analysis. Concordance between observed and predicted SF was $74 \%$ in 2000 and $82 \%$ in 2001 .

\begin{tabular}{llccccc}
\hline Year & Effect & df & Slope & SE of slope & Wald $\chi^{2}$ & $P$ \\
\hline 2000 & TL & 1 & -0.011 & 0.005 & 4.0 & 0.045 \\
& Period & 3 & & & 7.9 & 0.048 \\
2001 & TL & 1 & -0.011 & 0.003 & 12 & 0.0005 \\
& Period & 8 & & & 35 & $<0.0001$ \\
\hline
\end{tabular}

did not influence the rate of change in POFs, we used a single set of criteria to distinguish day- 0 and day- 1 POFs. These criteria were similar to those reported by White et al. (2003). An assumption of our SF estimation method is that hydrated oocytes represent eggs that are to be spawned that day (Hunter and Macewicz 1985). Two violations of this assumption that would cause us to overestimate SF are possible. One violation would occur if females spawned a partial batch on one day and retained the remainder as hydrated oocytes rather than resorbing them; if collected on the day after spawning, their ovaries would have both day-1 POFs and hydrated oocytes and these females would be interpreted as spawning twice in $2 \mathrm{~d}$ (i.e., $\mathrm{SF}=1$; Table 2). This violation appears unlikely, because other studies and our own observations suggest that retention of residual hydrated oocytes is infrequent. For example, in the multiple-spawning queenfish Seriphus politus, $0.1 \%$ of a batch may be retained (DeMartini and Fountain 1981). When we scored tautog ovaries as positive for hydrated oocytes, the frequency of such oocytes was too great to be consistent with a small rate of retention. Another violation of the assumption would occur if females did not spawn at all on the day that they produced hydrated oocytes but instead retained the entire batch for spawning another day. We cannot assess from our samples whether overnight batch retention occurs. Accurate scoring of this possibility would require collecting females shortly after spawning; judging from reports of spawning time and our postspawn observations of hydrated oocyte appearance, sampling in the late afternoon to dusk would be best.

We assumed that any temporal changes in spawning activity at our sampling site were representative of the population. In other words, we sampled at what we regard as a representative spawning ground. The spatial distribution of spawning in LIS is not well studied, and it is possible that spawning commenced before or continued after fish left the area. A set of entrainment samples at a nearby power plant intake provides a a)

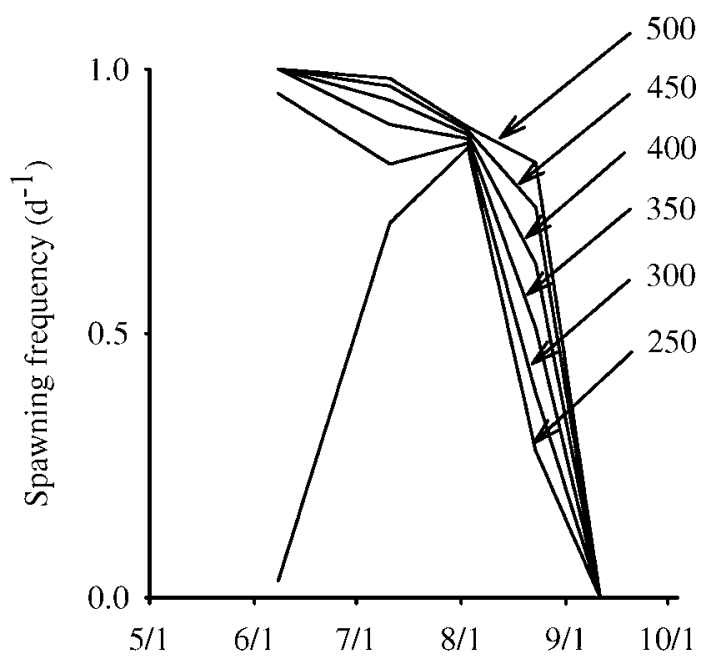

b)

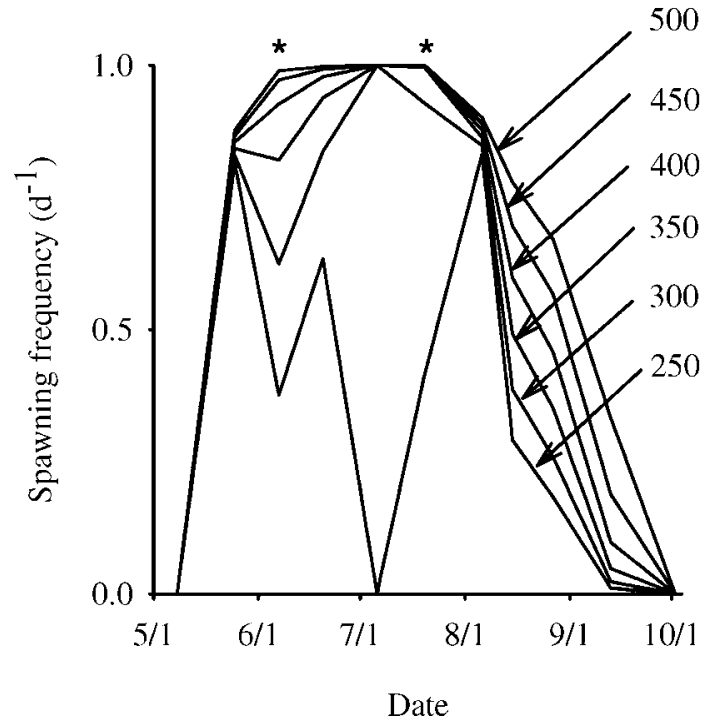

Figure 5.-Predicted size- and date-specific spawning frequency of female tautog in Long Island Sound during (a) 2000 and (b) 2001. Spawning frequency (see Figure 4) is plotted against date based on equation (5). Separate predictions are provided for size-classes ranging from 250 to $500 \mathrm{~mm}$ TL in 50-mm increments. Asterisks denote dates on which the size effect on spawning frequency was significant.

useful temporal comparison for our data; in 2000 and 2001, tautog eggs were first recorded on 14 June and 30 May, respectively (Millstone Environmental Laboratory 2006). These dates are both close to our first collections of reproducing females. 


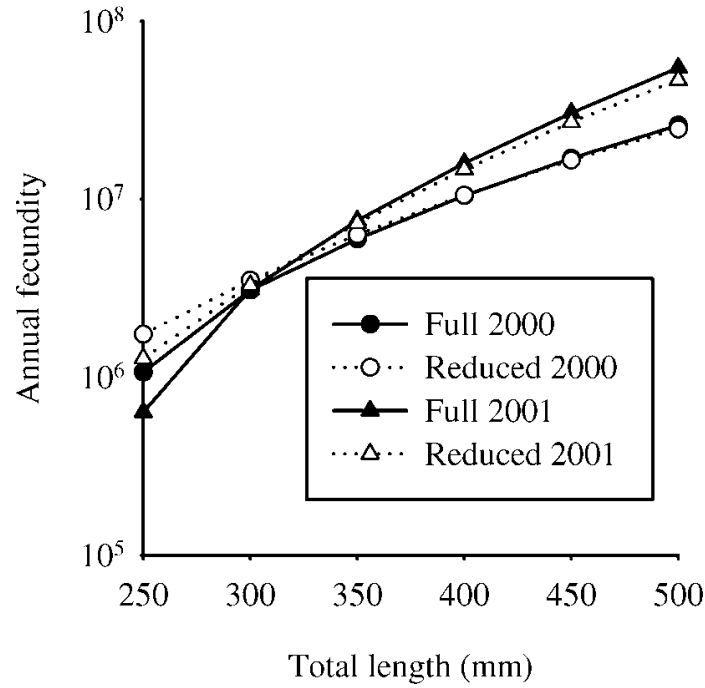

FIGURE 6.-Predicted annual fecundity of female tautog in Long Island Sound during 2000 and 2001. Annual fecundity is plotted against size based on equation (8) (the full model, which included size dependence) and equation (9) (the reduced model, which excluded size dependence).

Our estimates of tautog AF were greater than those previously reported by White et al. (2003) because of differences in study design or geographical differences in life history. White et al.'s (2003) analysis found that the AF of Virginia tautog increased from $2.9 \times 10^{4}$ eggs for age- 3 females $(275 \mathrm{~mm})$ to $10 \times 10^{5}$ eggs for age-9 females $(511 \mathrm{~mm})$. Females of comparable size in our analyses produced $1.0 \times 10^{6}$ and $55 \times 10^{6} \mathrm{eggs}$, respectively. Differences between the studies may be explained by differences in AF models. Our model incorporated the effects of both female size and intraseasonal variations into estimates of $\mathrm{AF}$. White et al. (2003) used a single value for SF and season duration for all sizes, whereas we estimated size dependence in both parameters. Omission of individual state variables (e.g., age, size, and condition) can sharply bias estimates of AF (Marteinsdottir and Begg 2002; Ganias et al. 2003). Furthermore, our sampling was designed to collect mature females over a broad size range on each sampling date. In contrast, females used in BF analyses by White et al. (2003) were from collections that occurred early in the season ( 24 of 29 females were collected within the first 3 weeks of the breeding season).

An alternative explanation for the differences in $\mathrm{AF}$ estimates between our study and that of White et al. (2003) is that LIS tautog have a greater AF than Virginia tautog. In particular, the appearance of spent Virginia females in June (see also Hostetter and
Munroe 1993) suggests that the spawning season may be more truncated there than in LIS. Other differences in life history between northern and southern tautog have previously been reported (Hostetter and Munroe 1993). The differences in phenology and life history may be attributable to genetic differences or environmental effects. Some genetic evidence indicates that northern and southern tautog are distinct stocks (Choudhury 2005; but see Orbacz and Gaffney 2000). East Coast fishes are distributed along sharp geographic gradients in productivity, seasonality, and other environmental variables, and these gradients have promoted differentiation in life history, behavior, and morphology (Conover 1992; Conover et al. 2005). Even when there is free genetic exchange, differences in $\mathrm{AF}$ and other life history traits may appear as purely phenotypic responses to gradients in productivity or other environmental factors.

The interannual differences in AF observed in this study may be explained by the variability in environmental conditions observed in 2000 and 2001. Seasonal egg output appeared to be greater in 2001 for females larger than $300 \mathrm{~mm}$. Some of the difference between years in our estimate of seasonal egg output may be attributed to the fact that collecting began later in 2000, and we evidently missed the onset of the breeding season. Our first collection in 2000 (May 25) yielded females in a hydrated state, meaning they were likely to spawn that day (Hunter et al. 1985). If the spawning season commenced prior to our collection effort, our summation would underestimate AF for female sizeclasses that spawned prior to May 25. The 400-mm and larger females produced larger batch sizes in 2001, and their reproductive peak lasted longer in 2001 than 2000, suggesting that they were indeed more productive overall. Variations in BF, SF, and season duration are often influenced by environmental conditions such as temperature (Kjesbu et al. 1998) and food availability (Hunter and Goldberg 1980; DeMartini 1991; Ali and Wootton 1999; Kraus et al. 2000). There were temperature differences between years; in June, nearshore water was up to $2^{\circ} \mathrm{C}$ cooler in 2000 than in 2001 (LaPlante and Schultz 2002). Thereafter, temperatures in both years were quite similar. There is evidence that feeding conditions were considerably better in 2001: the condition of females (size-adjusted nonreproductive mass) was $9 \%$ greater in 2001 than in 2000 . Because we did not remove gut contents before weighing, it is not clear whether the condition difference reflects greater energy stores or greater gut fullness.

Spawning frequency and BF both increased with female size. The scaling of $\mathrm{BF}$ is often roughly isometric, meaning that the slope of $\mathrm{BF}$ versus length is usually about 3 (Bagenal 1978). This was the case in 
a)

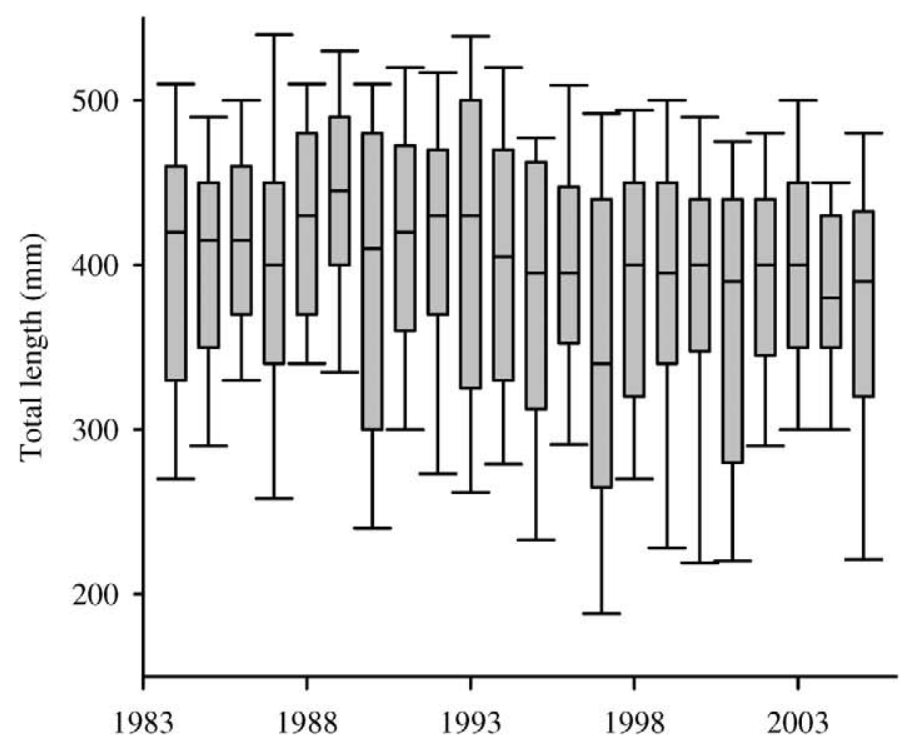

b)

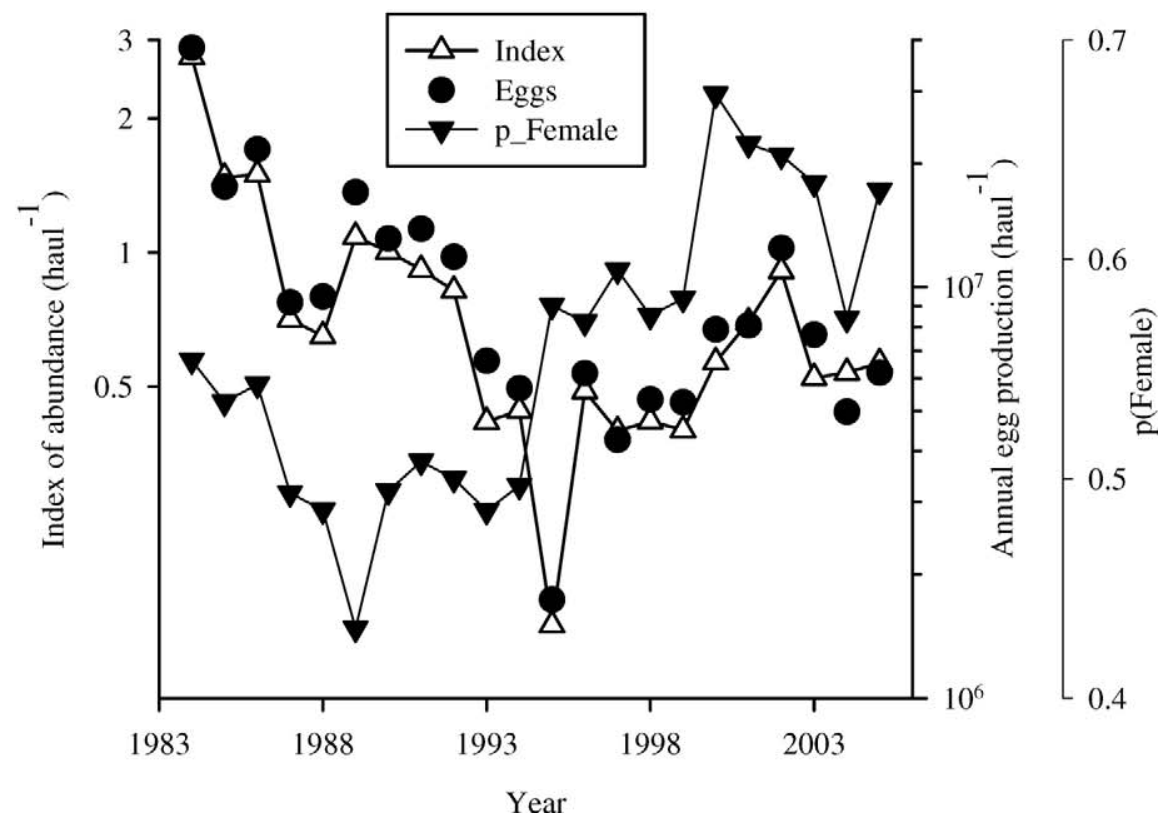

FIGURE 7.- Interannual changes in the size structure, abundance, and reproductive output of tautog in Long Island Sound. Panel (a) shows the size distribution of females (in each box, the center line represents the median, the lower and upper boundaries the 25th and 75th percentiles, and the error bars the 10th and 90th percentiles). Panel (b) shows the population abundance index (mean number per standardized trawl haul), sex ratio (proportion female), and reproductive output (expected seasonal mean number of eggs from females per standardized haul based on the full model for 2001 [Figure 6]). 
our 2000 data set. In contrast, in 2001 the slope was well above the isometric value, suggesting that larger females were drawing on relatively greater energy reserves or feeding at relatively higher rates to fuel relatively large batches of eggs. The effects of size and date on $\mathrm{BF}$ were additive, that is, the difference between larger and smaller females remained roughly constant as BF changed over the season. In both years, larger females spawned more frequently, as has been reported for Mediterranean sardine Sardina pilchardus sardina (Ganias et al. 2003) and bluehead wrasse Thalassoma bifasciatum (Schultz and Warner 1991). The effects of size and date on SF were nonadditive; on some dates, SF was relatively similar with size, while on other dates there was a strong size effect. It might be expected that the size effect would be small on dates in the middle of the reproductive season, when reproductive rates are generally high (SF close to 1 ), but this was not evident.

The relative AF is quite high, indicating that female tautog produce masses of eggs that are multiples of their own body mass each season. Our estimate of relative fecundity over the season ranged from nearly 3,000 to $19,000 \mathrm{eggs} / \mathrm{g}$ of total wet mass. These values are comparable to those reported for other coastal temperate fishes that spawn small planktonic eggs. For example, mature first-year northern anchovy Engraulis mordax produce almost 3,000 eggs/g over a season, while age-4 and older females produce more than $18,000 \mathrm{eggs} / \mathrm{g}$ (Parrish et al. 1986). Weakfish Cynoscion regalis produce about 20,000 eggs/g (estimated from data in Lowerre-Barbieri et al. 1996). Relative fecundity can be converted into proportional mass terms by estimating the mass of all eggs produced over the season and comparing it to the mass of females of different length (our unpublished data; see also Hostetter and Munroe 1993). Tautog eggs, as well as others that are broadcast-spawned into the water column, tend to be $1 \mathrm{~mm}$ in diameter or smaller. Choosing a mean diameter of $0.85 \mathrm{~mm}$ (Auster 1989) and assuming that eggs have the same specific gravity as the body (which is an underestimate), we estimate that $250-\mathrm{mm}$ females produce about their body mass in eggs over a season, while 500-mm females produce more than six times their mass of eggs over a season. Analysis of clutch dry mass or energy would be instructive for determining how much energy is invested by females over an entire season.

Because we focused here on reproductive output in terms of egg number, we did not analyze the effects of female size on other components of reproductive performance, such as egg size. Larger females of many species produce larger eggs with higher hatching rates, yielding larvae that survive at higher rates (Trippel et al. 1997). If larger larvae with higher survival rates hatch from the eggs of larger females, then realized fecundity in terms of surviving offspring will increase even more sharply with size than our analyses indicate.

The disproportionate contribution of propagules by large females can be quantified in terms of absolute fecundity, relative fecundity, and proportional contribution to the present stock. Relative to small (250-mm) females, large $(500-\mathrm{mm})$ females produced roughly 20-90 times more eggs in absolute terms and 3-10 times more eggs in relative terms. The proportional contribution of eggs by large females can be illustrated by comparing size and egg output distributions. In the 2005 trawl survey sample, the median female TL was $385 \mathrm{~mm}$. We estimate that females larger than this produced $83 \%$ of the eggs that year; $50 \%$ of the eggs were produced by $450-\mathrm{mm}$ and larger females.

Reduction in the relative abundance of large females could have a pronounced effect on the reproductive output of the population. Over a period of more than two decades, the abundance of tautog has decreased and the size structure has shifted to smaller fish, possibly as the result of harvest and environmental changes. Populations subject to size-selective fisheries are more vulnerable to recruitment overfishing (Trippel et al. 1997; Berkeley et al. 2004), as well as alterations of life history and other deleterious changes (Conover et al. 2005). To assess the potential for undetected changes in the reproductive capacity of LIS tautog, we compared the decline in overall abundance in a trawl survey to the decline in estimated egg output. Despite the change in female size distribution, the reproductive capacity of the population appears to have declined no more than its abundance. The abundance of females has increased relative to that of males (i.e., there has been a sex ratio shift), probably due at least in part to the larger size at age of males (Cooper 1967; Hostetter and Munroe 1993). An important caveat is that our analysis applied a single year's fit between AF and female size without regard to interannual changes in environmental conditions or compensatory responses. The omission of potential compensatory responses (outlined in Trippel et al. 1997) yields a conservative test of the hypothesis that egg production has declined more than the index of abundance, because we used egg production estimates near the end of the time series, when abundance was low. It is possible that depensatory processes are also occurring; perhaps the relatively low abundance of males has limited their availability to females, which could explain the few occasions in which we collected females that apparently contained eggs from the previous day.

The large impact of female size on AF in tautog has important implications for management of this species. 
The fishery for tautog has a minimum size $(350 \mathrm{~mm}$ from Massachusetts to Virginia) and no maximum size limit. Protection of large individuals is critical to recovering this population and others. We recommend implementation of management practices (e.g., slot limits) that are designed to protect larger, older individuals.

\section{Acknowledgments}

This research was supported by grants from Northeast Utilities Company, Connecticut Sea Grant, and the John Rankin, Jr., Ralph Wetzel, and Walter R. Whitworth Endowments to the Department of Ecology and Evolutionary Biology at the University of Connecticut and the Connecticut State Museum of Natural History. Research was conducted under protocol number V2701001 approved by the Institutional Animal Care and Use Committee. The Connecticut Veterinary Diagnostic Laboratory prepared histology samples. Laboratory fish were provided by CDEP. The success of the study relied on generous field assistance from the following people: C. Cooper, D. Cohen, B. DeGoursey, D. Dodge, J. Foertch, J. Godfrey, and J. Swenarton. Laboratory work and assistance in fish care were provided by S. Bullard, S. Colin, T. Fisk, N. Gauthier, T. Wyatt, and S. Zappulla. The following people provided technical expertise: J. LaPlante, B. Macewicz, and D. Miller; D. Simpson kindly assisted with the LISTS data set. The authors also thank P. Auster, J. Vokoun, D. Simpson, and $\mathrm{K}$. Wells for critical comments made on earlier versions of this manuscript.

\section{References}

Alheit, J. 1988. Reproductive biology of sprat (Sprattus sprattus): factors determining annual egg production. Journal du Conseil International pour l'Exploration de la Mer 44:162-168.

Ali, M. L., and R. J. Wootton. 1999. Effect of variable food levels on reproductive performance of breeding female three-spined sticklebacks. Journal of Fish Biology 55:1040-1053.

Arendt, M. D., J. A. Lucy, and T. A. Munroe. 2001. Seasonal occurrence and site-utilization patterns of adult tautog, Tautoga onitis (Labridae), at man-made and natural structures in lower Chesapeake Bay. U.S. National Marine Fisheries Service Fishery Bulletin 99:519-527.

Atlantic States Marine Fisheries Commission. 2006. Tautog stock assessment report for peer review. Atlantic States Marine Fisheries Commission, Stock Assessment Report 06-02 (Supplement), Washington, D.C.

Auster, P. J. 1989. Species profiles: life histories and environmental requirements of coastal fishes and invertebrates (north and mid-Atlantic), tautog and cunner. U.S. Fish and Wildlife Service Biological Report 82(11.105).

Bagenal, T. B. 1978. Aspects of fish fecundity. Pages 75-101 in S. D. Gerking, editor. Ecology of freshwater fish production. Wiley, New York.

Berkeley, S. A., M. A. Hixon, R. J. Larson, and M. S. Love. 2004. Fisheries sustainability via protection of age structure and spatial distribution of fish populations. Fisheries 29(8):23-32.

Buckley, L. J., A. S. Smigielski, T. A. Halavik, E. M. Caldarone, B. R. Burns, and G. C. Laurence. 1991. Winter flounder reproductive success, II. Effects of spawning time and female size on size, composition, and viability of eggs and larvae. Marine Ecology Progress Series 74:125-135.

CDEP (Connecticut Department of Environmental Protection). 2006. A study of marine recreational fisheries in Connecticut: job 2-marine finfish survey. Federal Aid in Sport Fish Restoration, Project F-54-R-24, Annual Performance Report. Available: www.ct.gov/dep/lib/dep/ fishing/general_information/MarineFishSurveyReport. pdf. (December 2006).

Choudhury, A. 2005. The use of microsatellite DNA fingerprinting for aquaculture and fisheries science. Doctoral dissertation. University of Rhode Island, Kingston.

Conover, D. O. 1992. Seasonality and the scheduling of life history at different latitudes. Journal of Fish Biology 41B:161-178.

Conover, D. O., S. A. Arnott, M. R. Walsh, and S. B. Munch. 2005. Darwinian fishery science: lessons from the Atlantic silverside (Menidia menidia). Canadian Journal of Fisheries and Aquatic Sciences 62:730-737.

Cooper, R. A. 1966. Migration and population estimation of the tautog, Tautoga onitis (Linnaeus), from Rhode Island. Transactions of the American Fisheries Society 95:239247.

Cooper, R. A. 1967. Age and growth of the tautog, Tautoga onitis (Linnaeus), from Rhode Island. Transactions of the American Fisheries Society 96:134-142.

DeMartini, E. E. 1991. Annual variations in fecundity, egg size, and the gonadal and somatic conditions of queenfish Seriphus politus (Sciaenidae). U.S. National Marine Fisheries Service Fishery Bulletin 89:9-18.

DeMartini, E. E., and R. K. Fountain. 1981. Ovarian cycling frequency and batch fecundity in the queenfish, Seriphus politus: attributes representative of serial spawning fishes. U.S. National Marine Fisheries Service Fishery Bulletin 79:547-560.

Ganias, K., S. Somarakis, A. Machias, and A. J. Theodorou. 2003. Evaluation of spawning frequency in a Mediterranean sardine population (Sardina pilchardus sardina). Marine Biology 142:1169-1179.

Hoelker, F., and B. Breckling. 2005. A spatiotemporal individual-based fish model to investigate emergent properties at the organismal and the population level. Ecological Modelling 186:406-426.

Hostetter, E. B., and T. A. Munroe. 1993. Age, growth, and reproduction of tautog Tautoga onitis (Labridae: Perciformes) from coastal waters of Virginia. U.S. National Marine Fisheries Service Fishery Bulletin 91:45-64.

Hunter, J. R., and S. R. Goldberg. 1980. Spawning incidence and batch fecundity in northern anchovy, Engraulis mordax. U.S. National Marine Fisheries Service Fishery Bulletin 77:641-652. 
Hunter, J. R., N. C. H. Lo, and R. J. H. Leong. 1985. Batch fecundity in multiple spawning fishes. Pages 67-77 in R. Lasker, editor. An egg production method for estimating spawning biomass of pelagic fish: application to the northern anchovy, Engraulis mordax. NOAA Technical Report NMFS 36.

Hunter, J. R., and B. J. Macewicz. 1985. Measurement of spawning frequency in multiple spawning fishes. Pages 79-94 in R. Lasker, editor. An egg production method for estimating spawning biomass of pelagic fish: application to the northern anchovy, Engraulis mordax. NOAA Technical Report NMFS 36.

Kjesbu, O. S., P. R. Witthames, P. Solemdal, and M. G. Walker. 1998. Temporal variations in the fecundity of Arcto-Norwegian cod (Gadus morhua) in response to natural changes in food and temperature. Journal of Sea Research 40:303-321.

Kraus, G., A. Muller, K. Trella, and F. W. Koster. 2000. Fecundity of Baltic cod: temporal and spatial variation. Journal of Fish Biology 56:1327-1341.

LaPlante, L. H., and E. T. Schultz. 2002. Estimating the annual fecundity of tautog (Tautoga onitis) in Long Island Sound. Final Report submitted to Northeast Utilities, Dominion Power Station, Waterford, Connecticut.

Lisovenko, L. A., and D. P. Andrianov. 1991. Determination of absolute fecundity of intermittently spawning fishes. Journal of Ichthyology 31(9):143-155.

Lowerre-Barbieri, S. K., and L. R. Barbieri. 1993. A new method of oocyte separation and preservation for fish reproduction studies. U.S. National Marine Fisheries Service Fishery Bulletin 91:165-170.

Lowerre-Barbieri, S. K., M. E. Chittenden, and L. R. Barbieri. 1996. Variable spawning activity and annual fecundity of weakfish in Chesapeake Bay. Transactions of the American Fisheries Society 125:532-545.

Lowerre-Barbieri, S. K., J. M. Lowerre, and L. R. Barbieri. 1998. Multiple spawning and the dynamics of fish populations: inferences from an individual-based simulation model. Canadian Journal of Fisheries and Aquatic Sciences 55:2244-2254.

Marteinsdottir, G., and G. A. Begg. 2002. Essential relationships incorporating the influence of age, size, and condition on variables required for estimation of reproductive potential in Atlantic cod Gadus morhua. Marine Ecology Progress Series 235:235-256.

Mazaris, A. D., and Y. G. Matsinos. 2006. An individualbased model of sea turtles: investigating the effect of temporal variability on population dynamics. Ecological Modelling 194:114-124.

Millstone Environmental Laboratory. 2006. Annual Report 2005: monitoring the marine environment of Long Island Sound at Millstone Power Station, Waterford, Connecticut. Dominion Resources Services, Waterford, Connecticut.

Munch, S. B., M. Mangel, and D. O. Conover. 2003. Quantifying natural selection on body size from field data: winter mortality in Menidia menidia. Ecology 84:2168-2177.

Munroe, T. A. 2002. Family Labridae. Pages 448-466 in B. B.
Collette and G. K. MacPhee, editors. Bigelow and Schroeder's fishes of the Gulf of Maine. Smithsonian Institution Press, Washington, D.C.

Newman, M. 1993. Regression analysis of log-transformed data: statistical bias and its correction. Environmental Toxicology and Chemistry 12:1129-1133.

Olla, B. L., and C. Samet. 1977. Courtship and spawning behavior of the tautog, Tautoga onitis (Pisces: Labridae), under laboratory conditions. U.S. National Marine Fisheries Service Fishery Bulletin 75:585-599.

Orbacz, E. A., and P. M. Gaffney. 2000. Genetic structure of tautog (Tautoga onitis) populations assayed by RFLP and DGGE analysis of mitochondrial and nuclear genes. U.S. National Marine Fisheries Service Fishery Bulletin 98:336-344.

Parrish, R. H., D. L. Mallicoate, and R. A. Klingbeil. 1986. Age dependent fecundity, number of spawnings per year, sex ratio, and maturation stages in northern anchovy, Engraulis mordax. U.S. National Marine Fisheries Service Fishery Bulletin 84:503-517.

Schultz, E. T., L. M. Clifton, and R. R. Warner. 1991. Energetic constraints and size-based tactics: the adaptive significance of breeding schedule variation in a marine fish (Embiotocidae: Micrometrus minimus). American Naturalist 138:1408-1430.

Schultz, E. T., and R. R. Warner. 1991. Phenotypic plasticity in life history traits of female Thalassoma bifasciatum (Pisces: Labridae), 2. Correlation of fecundity and growth rate in comparative studies. Environmental Biology of Fishes 30:333-344.

Scott, B., G. Marteinsdottir, and P. Wright. 1999. Potential effects of maternal factors on spawning stock-recruitment relationships under varying fishing pressure. Canadian Journal of Fisheries and Aquatic Sciences 56:1882-1890.

Sogard, S. 1997. Size-selective mortality in the juvenile stage of teleost fishes: a review. Bulletin of Marine Science 60:1129-1157.

Sprugel, D. G. 1983. Correcting for bias in log-transformed allometric equations. Ecology 64:209-210.

Stolgitis, J. A. 1970. Some aspects of the biology of the tautog, Tautoga onitis (Linnaeus), from the Weweantic River estuary, Massachusetts, 1966. Master's thesis. University of Massachusetts, Boston.

Trippel, E. A., O. S. Kjesbu, and P. Solemdal. 1997. Effects of adult age and size structure on reproductive output in marine fishes. Pages 31-62 in R. C. Chambers and E. A. Trippel, editors. Early life history and recruitment in fish populations. Chapman and Hall, London.

White, G. G., T. A. Munroe, and H. M. Austin. 2003. Reproductive seasonality, fecundity, and spawning frequency of tautog (Tautoga onitis) in the lower Chesapeake Bay and coastal waters of Virginia. U.S. National Marine Fisheries Service Fishery Bulletin 101:424-442.

Williams, E. H., and K. W. Shertzer. 2005. Effects of fishing on growth traits: a simulation analysis. U.S. National Marine Fisheries Service Fishery Bulletin 103:392-403. 